\title{
DISCLAIMER
}

This report was propared as an etcount of wort uponacred by an asency of the United Sintes (bovernment. Nolther the Unlied Situle (twornmont nor any agency thereof, nor uny of thelr employoen, mates any warranty, expres or Impltad, or auumen any lefal libbility or reuponalhillty for the aceuracy, completeneen, of unofulnea of any informalion, apparatun, product, of

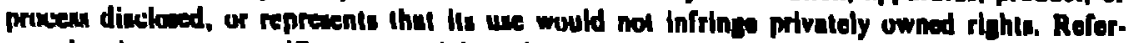
onse hereln lo any arecific commercial prodiset, procean, of ervica hy irade numo, tradomark,

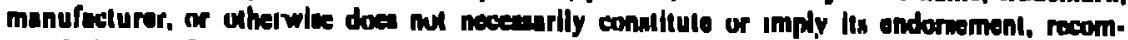
mendalton, or fuvoring by the Unlied Siates (lovernment or any uponcy thereof. The vlew and opinions of authorn expresual herein dn not necesurilly ante of reflect these of the Unlied Bitatea (hwernment or any agency thereor. 


\section{EXPERT ASSISTANTS FOR DESIGN}

Jack Aldridge, John Cerutti, Willard Draisin, Michael Steuerwalt

Los Alamos National Laboratory

Los Alamos, NM 87545

\section{INTRODUCTION}

Christopher Alexander [2] describes arcbilectural design as a process whose objecive is to produce a form that, has oo serious mismatches with the environment defined by its use. Often the environment is incompletely defined and is almost certain to change over time. A similar description applies to nuclear weapon design because specification details $v$ ary with refinement of the scenario for using the weapon and with design changes in related equipment such as the delivery vebic!e. The form of a weapon might mismatch the delivery vehicle geometry or carrying capacity, the con. ditions under which it is delivered, or even the efects it is inteoded to create.

In practice, a design results from many iterations of the process of balancing objectives against constraints. Because for complex designs these iterations are expensive, we cre evaluating whether systens using techaiques of artifcial intelligence (AI) can improve the process and provide corporate memory botb of successful designs and of the process itself. In this paper, we describe two such expert p:ograms currently under development at the Los Alamos National Laboratory, PRCCON and the Designer's Apprentice. We ernphasize the Apprentice because PRCCON has been described elsewhere $(3,4)$. Botb codes define incerfaces to simulations that provide wide variety of information about the performance of complex devices. We expect that the systems will help designers understand and use this information more effectively. We also believe that the systems will belp users incorporate moie factors early in the design process and so avoid attempts to optimize subsystems later. By so managios the tow of information, PROCON and the Apprentice should belp achieve better designs.

In rection 2 we discuss import sat factors of the interface. Section 3 outlinet bow Al techniques can belp. In the last :wo sections we take up PROCON and th: Apprentice.

\section{INTERFACES: ACCESS TO THF TOOLS}

Computer codes that simulate complex aystems play a vital role in understanding and dyoigaing those systems. They provide critical information about important charac. teristics, such as timing $|0|$, strength, electromagnetic beld patterne $|7|$, and aystem behavior |1|. Beyond this, exteasive oumerical simulation of ceveral veraions of a oy tem is uften cheaper than constructing even one teal version. 
But codes to simulate complex oystems are themselves complex. To solve bis design problem, the designer must cope not only with the complieated phenomena he is trying to underatand but also with the complicated tool that simulates these pbenomena. Good interfaces to the simulation help the designe: build input to the code, run it, and interpret the results, by providing:

(1) error checks.

(2) a world model - a model of the thing being designed in its context,

(3) execution of the simulation.

(4) a dictionary of sy nonyms,

(5) sraphics and fltering.

(6) an assessment of input and output relationships,

(7) bistory

Input that describes the system being simulated should be checked for errors in format and in correlation between variables. This is passive assistance: the designer must create the input from scratch or by changing an existing input file. More active assistance is possible: an interface that bas a model of the world being simulated can help build the input. It can convert between units appropriate to the designer and units internal to the code, and can interpret between the designer's terminology and the code's names for variables. On a higher level, the world model establishes contextial information that the interface can use to assist the designer. For example, the designer may specily a material for part of a device. By maintaining a dictionary of terms, the interiace can understand that the material bas certain physical properties such as density and sbear strengtb. If the interface encodes this knowledge in tables or rules of an expert system, then the system can review a design for inadvertent errors aud remind the designer of problems. It is better that the system warn a designer, who may be trying oew concepts, than that it prevent indovation by forcine him to correct wat it considers to be an error. A dictionary of terms can also be viewed as a starting point for a "natural language" icterface |11|

Where the computational environment is complicated by the presence of several diflereat computers, operating systems. libraries, or simulation tools, the interface can $b=l p$ the designer choose properly. If an efective design requires runaing several simulation codes, the interface can provide synonyms for the diferea: names that codes use for the same variables. Thus the interface provides a single terminology for the designer.

The world model can be the basis for a graphical interaction with the desigaep - people process pictsres better than words. Usually simulation codes can provide a wide variety of output because someone might be interested in seeing these quantities sometime during the life of the simulation code. Most of this output is not something the designer wants to see all the time. The interface can Blter the output for the designer in the context of bis curreat needs. Likewise, it can determine when the results are no looger beeded.

An area that is often overlooked in design is sensitivity to parametric variatiun. Even in optimizing codes, lòere is often an emphasis on point desigo. Io thuse cases, information sbout ensitivity is usually expressed through parameter whose meanias is lesn than intuitive. Because sensitivity analyois cad be important, the incerface should hasdle it witbout requiring specifle instructions from the designer. The interface should give some qualitative indication of the effects of ehanges of input on out put parameterb.

Finally, a good interface can teep track of what has been done both on the current problem and un related ones. For the duration of the denigo problem, the systen can record design successes and failures and che resuits of sensitivity studies. Fur the longer term, the system can los ouccenful deaiga and compromises and the reason. for ibem. Serupdias the successful desiga makes it posaible to recall past 
work, and makes more accessible to designers the details of work in which they themselves may have had no direct part. Thus the interface represents a corporate memory - one not overwhelmed by curreat design fashions.

\section{HOW AI CAN HELP}

To build an interface vith all these capabilities Al tecbniques are essential. We wish to emphasize that not every part of the interface requires $\mathrm{AI}$, and that the concepts we are discussing are broadly applicable to derign activities and not just to nuclear weapon design.

Al tools for such an interface come from three areas: expert systems, planning, and natural language processing. An expert system, more properly referred to as a production system, consists of an inference engine and a data base. It can make a decision from a collection of rules that map decision factors to the conclusions and a declaration of what values the decision factors have for the current case. The expert system may be enbanced with the use of object-oriented programming and rules that match patterns $[5,8,12)$. A planner analyzes a task into a collection of goals. It furtber analyzes the goals into subgoals until a feasible process can be described. Planning may be extended to learning, in the sense that partial plans may be recorded by the system to belp deal with problems too complex for the original data base of procedures. Natural language processors are the third kind of cool we might use. Fortunately, the communications of concern to us are between computers and tend to be more formalized than communications between people, but many of the ideas from this field are applicable. Graphics packages, optimizers, and data base management systems complete the components with which we build the interfaces.

\section{PROCON}

PROCON is an intelligent production controller that provides an interface between designers and several simulation codes; it belps the designer set up and submit "production" calculations. PROCON ba tbree major parts: a user incerface, an error checker, and a job control stream generator. Inputs io the codes are opecifled by data base entries in the form of GLISP (9) objects in a Fratialisp entriroameat. Control functions that are part of PROCON use the fields of ttese objects to provide the interface and checking. However, control is not dependent on the data recorded in the data bases. Adding another code input involves creating appropriate objecte describing the input but needs no cbanges in the functions. Three simulation codes bave beed interfaced this way. The curpent thruat to the PROCON develor anent is to provide checking for correlation becween input parameters and for legat stracture of the input ale a a whole. We hope PROCON will eventually replace several pro grams now used to control simulation codes with a uingle prosiam that does more than curreat controllers and is easier to maintaio because of the data-driven pro sramming. We plan to put the sraphic interface deacribed below into PROCON and to use the job otream senerator from PROCCN wo mate the Deaigoer's Apprentice insensitive to change in our computios center's procedures and cont? ul languages.

\section{THE DESIGNER'S APPRENTICE}

The Designer's Apprentice is a prosiam that will provide a complete interface to the designer to senerate initial solutions to the design problem and to help bim une appropriate simulation codes. The Appreatice is wort in progrew. However, wo also discuse advanced concepts that ase not part of the original Apprentice but are litely to appear in later veruions. 
Because the Appreatice is composed of many interacting subparts, we decided to use the techniques of structured analysis and design [10] to control development. These techniques have proved valuable for organizing flow of information through the desigo process, uncovering subcomponent interacticas, and learning what subprocesses are contained in each facet of the overall design process. With such an overview in place, incremental code development and prototyping are proving useful. Fig. 1 sbows top-level data flow and a task hierarchy for the Apprentice.

Design begins with a set of explicit performance specifications and a set of implicit specifications such as safety, manufacturability, and cost. The specifications might include a nominal yield of the weapon, a range of yields, perbaps a type of

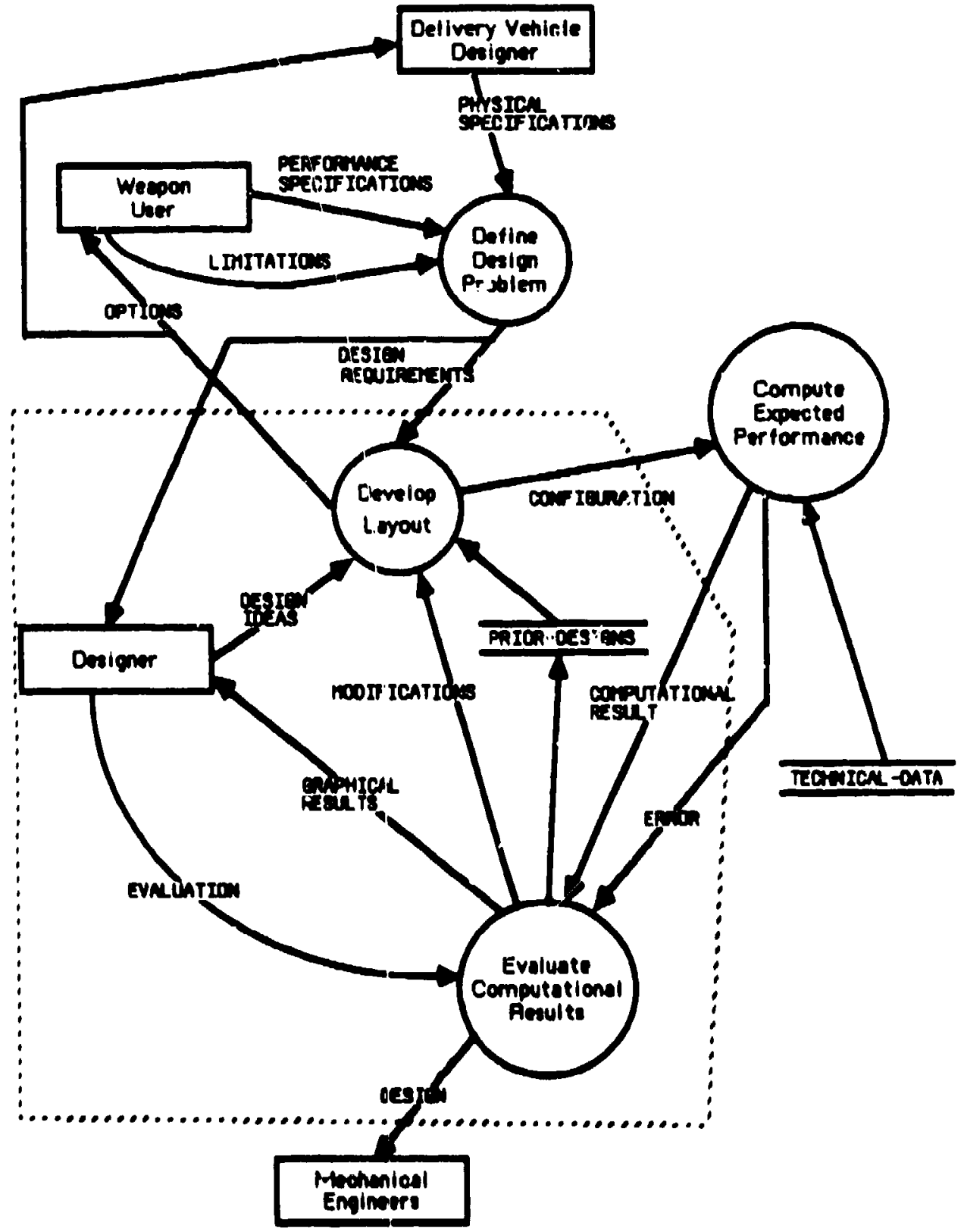

Fig. 1a. Bubble chart for the Designer's Appreatice. This cbart shows information dows and transformations of tows. The dotted area represeats the current role of a designer. 


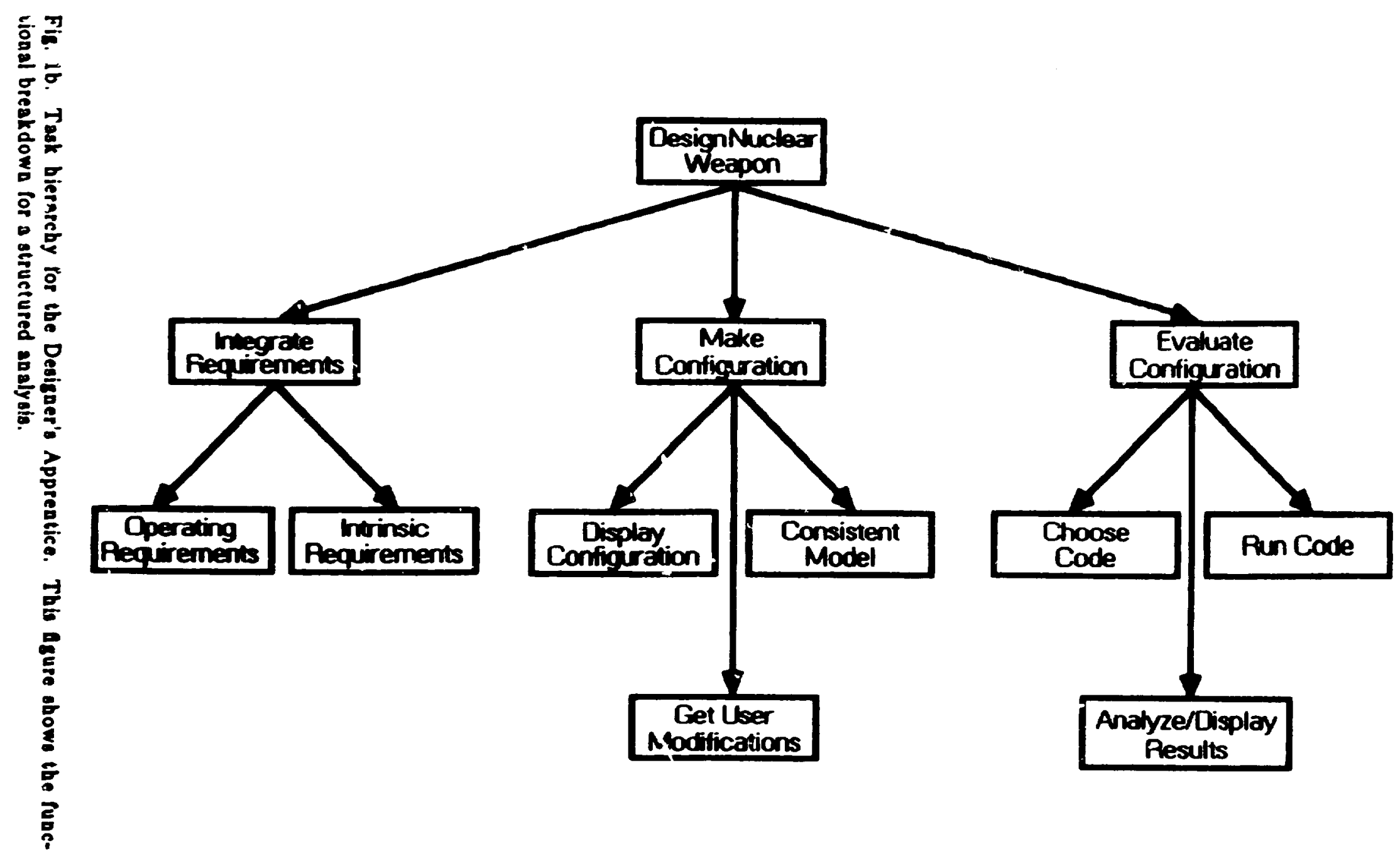


dominant radiation to be produced, and interfaces for those properties of the weapon that can afect the performance of a delivery vebicle; these propertien include limits for the weapon's dimensions, total mass, and location of its center of mass. Safety considerations in transportation and storage are of concern but are litely to be assumed ratber iban explicitly stated. Availability of materiab - particularly nucleas materials - at the time the eystems will be manufactored is an important consideration. These factors taken logetber provide the context for the desiga. The designer's tast is to geverate a form - 3 relation between materials in certain shapes - that meets the apecifications. (Alexander notes that ftting a context means eliminating misinatcbes not irying to decide what makes a "gnod" lorm.)

The designer must make an initial layout tbat specifes materials and shapes of parts. The Apprentice assists in this task graphically. Because we cannot deal bere with internal construction of nuclear weapons, we shall illustrate the interaction with a simple mechanical design example. The desired part is an end plate of an electric motor that holds the bearing and lubrication pads. The plate provides centering for the motor's apmature. The bearing can be removed if the armature needs replacemer:; tue plate aud armature can be removed as anit if need be. The plate must extend no furtber than $1 / 2$ inch beyond the end of the motor bousing. Drilled and lapped boles are provided in the motor bousing for six $1 / 4-20$ screws. The housing is $1 / 4$ inch thick at the screw radius of 1.25 incbes. The motor armature clears the inside end of the housing by no more than $1 / 8 \mathrm{inch}$. The armature must be aligned with the axis of the bousing to better than $0.010 \mathrm{inch}$. Several possible solutions are illustrated in Fig. 2.

We assume the designer's computational aids predict lifetime and lubrication needs for various bearings at various speeds with diflerent lutricants, and estimate manufacturing costs of items once the confguration is determined. A data base managemeut code can obtain discrete information such as bearing stocks, design standards sucb as tolerances, and so on. A more sophisticated program might op:imize witb respect to cost of materials and maoufacturing.

Even with the detailed specification given above, the designer aas a wide range of options to complete the tast. One is manulacturability - nuaterials and tolerances, manufacturing techoiques, edge specifcation, dimensions of parts. What kind of bearing is required? Which simulation codes need be run and what inpul information is needed to obtain the desired output? What surface Bnish is needed? What aesthetic lactors should be included? The cost of manufacture will depend on the
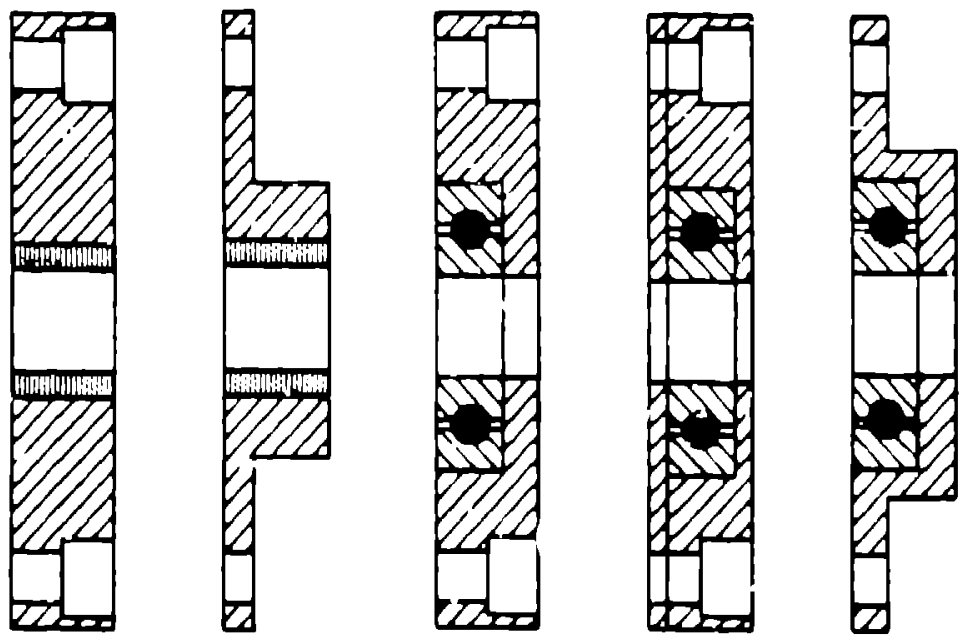

Fis. 2. Some design options for an end a ange of an electric motor. 
decisions made by the designer about all aspects of the desiga. In the auclear weapons case, meeting design criteria can lead to a need for developing new materials or new material bandling techniques, either of which is likeby to be expensive.

The design strategy is to use the specifications to develop 8 layout, then itera tively run the design codes and redefine configurations until all specifications are satisfied.

The frst task for the Apprentice is to determine what the designer is going to do during this session. He may want to continue the same problem be had last time (the default), specify a new problem, or make a radical change in his approach to the curient problem. A user profile that keeps track of what a particular designer is doing and what significant problems remaic is used to fod a siarting plare for the interaction with the designer.

The second task of design is to collect the specifications. In the Appreatice this is done with a user-modifiable menu. The menu is divided into a main group and a subsidiary group. Although be has access to all specifications, normally the designer is concerned only with the main set. Examples of main specifications are mass, seometry, design context, and yield. Examples of subsidiary specifications are salety issues and special output requirements. The designer may specify some or all of these factors. He may enter physical quantities as numbers with units he prefers. Ratber than clutter menus with examples of input syntax, throughout this interaction we use the instruction line to prompt the designer. The irstruction line - a standard part of the Lisp machine screen - shows information that helps explain other displays: samples of input syatax, suggestions about what to do next of how to do it, and 80 on. Fig. 3 shows an abbreviated specification menu as it resides on the designer's screen. Once the designer indicates be is foished witb the opeciflcations, an expert system reviews them to see if it can understand what to do next and to fill in values that the dasignet did not provide. It makes use of limited knowledge to assure that grosaly absurd specifcations are caught early. (Note that we must distinguish between no specification and a specification of zero for numerical values.)

Next, the graphical interaction to define the layout begins. Merely showing pictures of the design does not sufice. To be useful, they must be modifiable by an interaction with the screen and must scale properly to show dimensional changes io context. Often the designer can spot faults in the desiga from such pictures and correct the error immediately. Likewise, pictures are an excellent way to advise the designer of potential problems such as dimensions that are too small for mechanical stability. Of course, spotting these defects if one function of an expert prozram that is assisting the designer. Fig. 4 adds to Fig. 3 a warning that a thickness fault bas been spotted by the expert system.

Menus can focus attention on a part of the problem at a particular time. They can also ofer proper choices in a particular context. For example, if a plate has been designed, the meav might offer material as as option, and might even suggest appropriate miterialb. Fig. 5 illustraces bow such a meno might look to the designer. Choices of material could be determined by cost, policy, or manufacturability considerations. If the dasigner can get an explanstion whenever he want, then the oyetem can liat choices without comment.

Another aid to the designer in to have always visible the apecificatione and any values immediately computable from the design. An example of such a computation is the total mas of the object being designed. The dimeasions and type of material sive the volume of the material. Tables of densities give the anas and the sum of the masses of the parts is the total mas. Suct elementary calculations provide the designer with useful compsrisons without divepting bis attention from the problem at hand. The opeciflations display sleo provides another handy method of informins him of mismatches between his deaign and the specifcationo. 


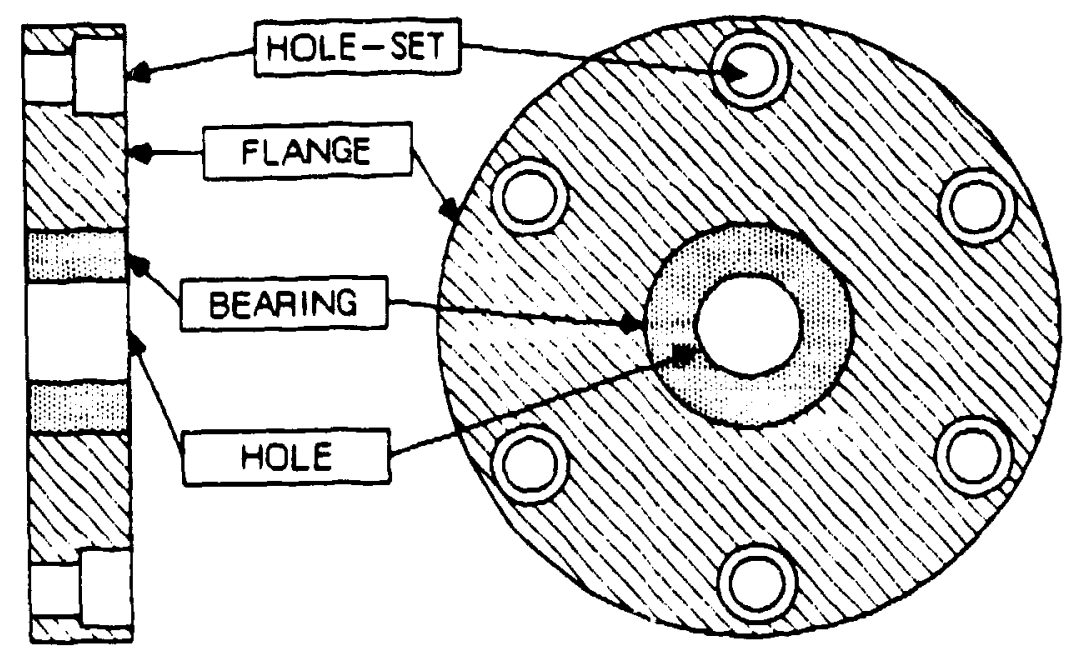

\begin{tabular}{|l|l|}
\hline & Soecifications \\
\hline Item & Spec \\
\hline Thickness $\leq 0.5$ inch 0.5 inch \\
Screws
\end{tabular}

Fig. 3. A sample graphic interface. Flags on the diagram are active. The speciflcations window is always present; it shows comparisons between the specifled values and those derived from the curreat design. Shading in the window indicates discrepancies.

The CAD features offered by the graphics are underpinaed by a program that syatbesizes objects (the objects of object-oriented programming). The Apprentice can use objects to do various tasks, such as prepare in puts to codes or make solid models of the forms being designed. One intelligent tast is to construct solid figures from lines. Anotber is to construct cross sections for a composite device based on descriptions of its components. The Appreatice uses dats bases of successful devices and designs, as well as heuristic rules, to sussest a solution to the design problem. The data base information and rule output are transformed in to weapon-design objects for the duration of the design problem. The objects bave subobjects that are the components of the device, with such attributes as dimensions, materials, and locations. By manipulating these objects, the Apprentice generates the inputs to the simulatiun codes and to the graphic interface. 


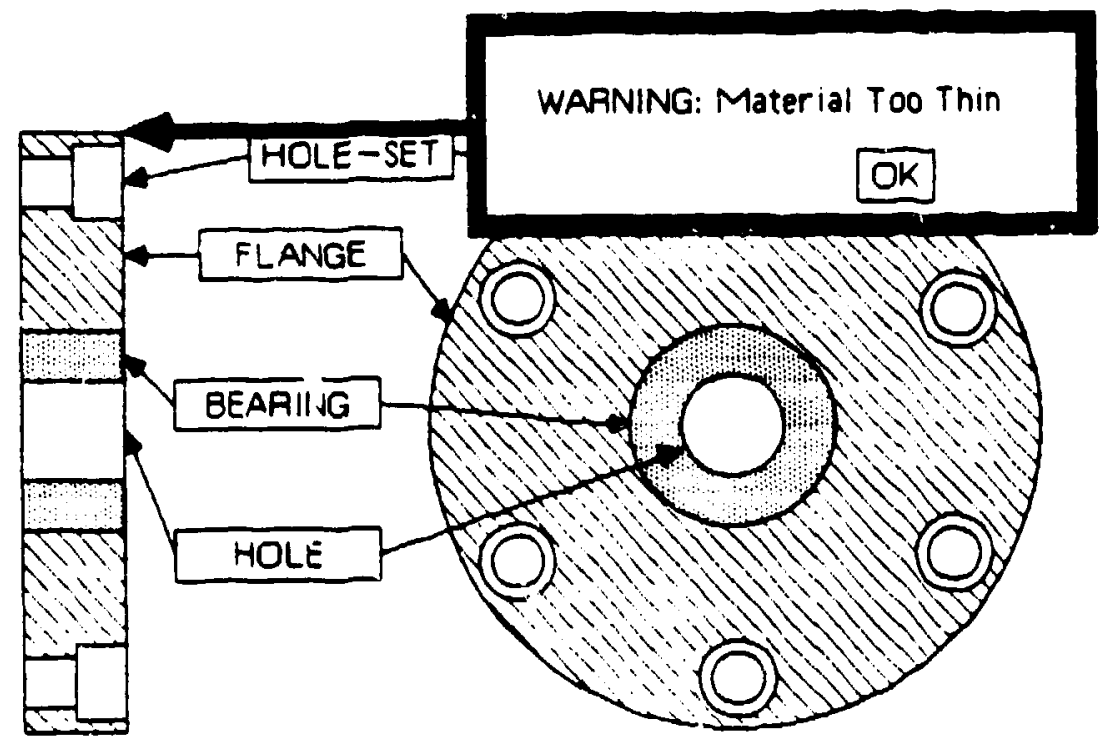

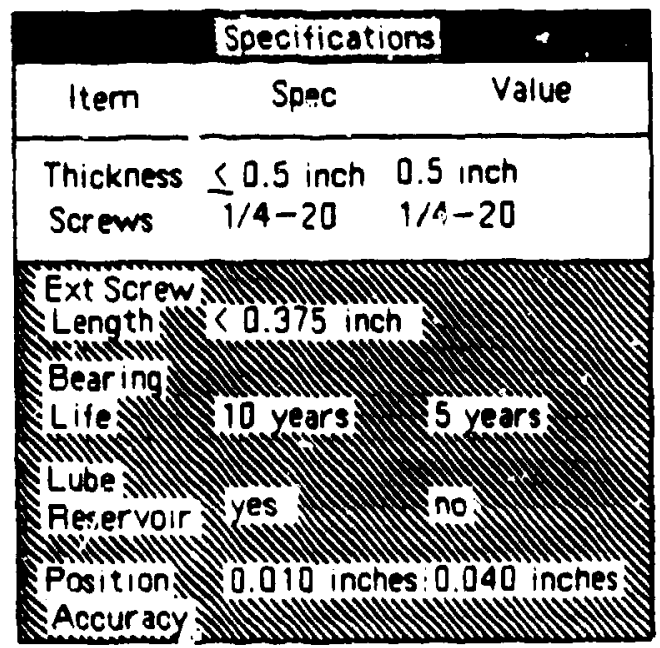

$\therefore$

Fig. 4. Same as Fig. 3, but with a warning that an expert system in the Apprentice has found a manufacturability fault.

The window system of a Lisp machipe can show more than one view of the design. An individual ccmponent or an expanded view of a section of the design may be displayed and changed in a second window. The basis for both images is a single object, so the two windows remain syachronized. Because objects are instantiations of an object description (a lavor, for example) the eavironment can hold several designs at once. By invoking the proper menus, the user can switch between desigas.

When the srapbic interaction concludes, the designer may choose to run simulation codes on our CRAY oupercomputers. For the Apprentice, thin entailu converting information in the sbjects on the Lisp machine into inputs to the simulation codes. Data bases of in puts to the desigo codes - variables, formats, order, correlations are maintained in the Lisp environment. The correspondence between object attri butes and these belds of the input ale is kept as well. We gote that because the designer communicates with the expert system in terns of the object attributes it is 


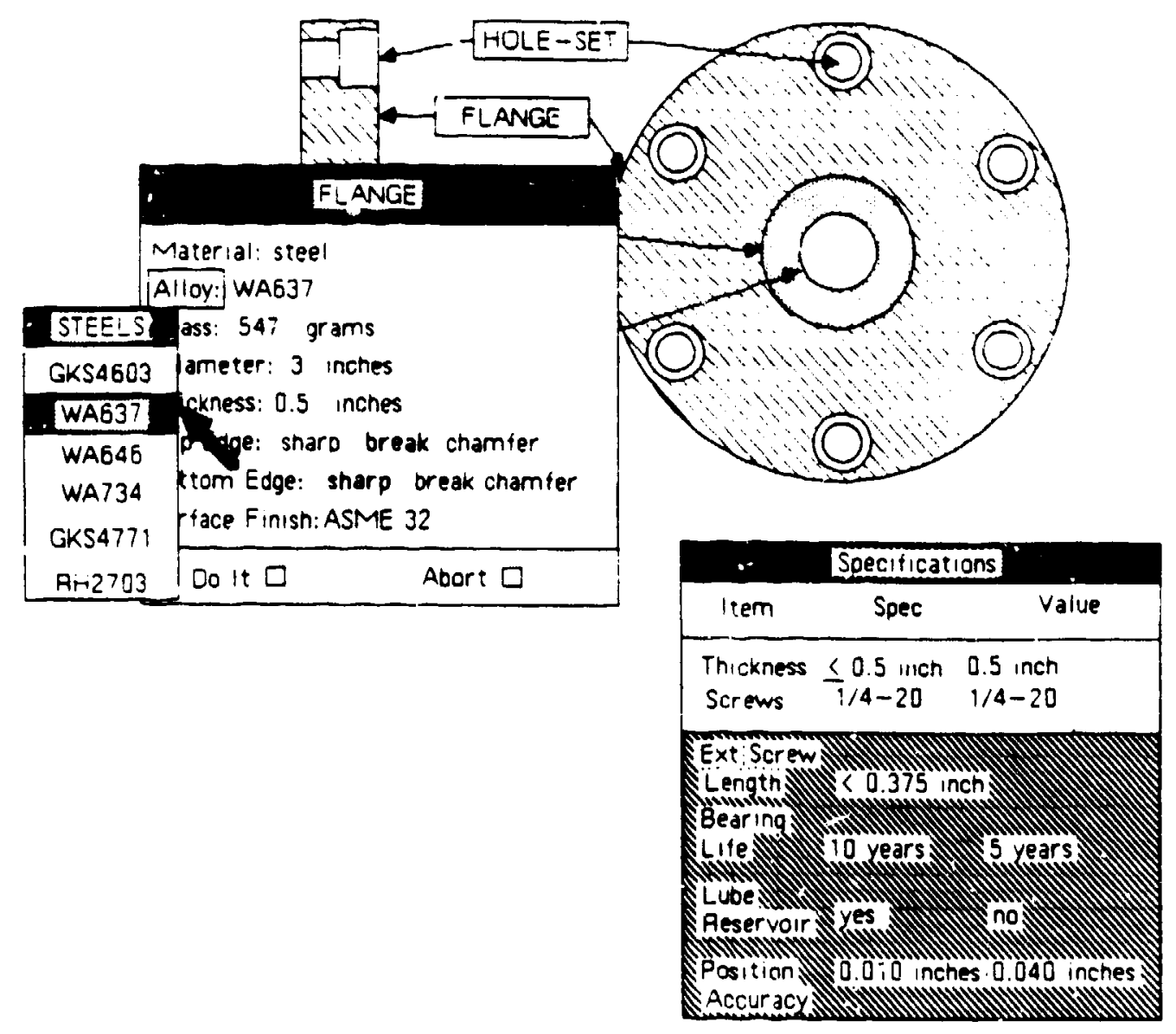

Fig. 5. Active windows at different levels of the Apprentice are obtained by successively choosiag the flag and the item in an associated pop-up menu.

possible to bave a uniform interface to several design codes. The designer only needs to be familiar with the terminology used to create the objects, oot the stylized input names that the simulation code wants.

Developing the input files that describe designs to simulation codes is the goal of the initial Designer's Appreatice. However, an obvious extension is to mak a the Apprentice control the computation and aualyze its results. Then the Apprentice might be able to provide appropriate graphs of computational results for a particular set of designs, or perhaps merely Giler the computer output. Implementing such capability would require adding data bases of computer output variables, drivers to process the information, and expert systems to monitor the status of the computation. Determining what io do next from the status of the computation would take a message-understanding expert system and a planner to create a procedure from acripts and partial plans. Such capability would make the Apprentice a true design partoer to the human, but is clei.rly not easy to achieve.

The test of whether PROCON and the Apprentice can belp designers is acceptance by the designers themselves. Few expert oystems bave had such acceptance. We hope that the combination of graphics, automatic input generation, and a variety of expert systems will prove to be tempting. 


\section{REFERENCES}

1. ACCOS V. National CSS, Ine, 542 Westport Ave, Norwalk, CT, 06851.

2. Alexander, C. (1964) Notes on the Synthesis of Form. Harvard University Press, Cambridge, MA: 24-27.

3. Aldridge, J.P., Cerutti, J.H., Drainio, W., and Stenerwalt, M. (1085) Expert Systems for Design and Simulation. To appear. Proceedings of the ALA/NASA Symposium on Automation, Robotics, and Advanced Computing for the National Space Program, Washington, DC, September 1985.

4. Draisin. W. and Peter, E. (1985) An Intelligent Interface for Design and Simular tion. Submitted to the Firat International Conference on Expert Database Systems, Charleston, SC, April 1986.

5. Fain, J., Hayes-Roth, F.. Sowizral, H., and Waterman, D. (1982) Programming in Rosie: An lntroduction by Means of Examples. Rand Report N-1646-ARPA.

6. Fallows, J.M. (1981) National Defense. Random House, NY: 76-95.

7. Halbach, K. and Holsinger, R.F. (1976) Superfah - A Computer Program for Evaluation of RF Cavities with Cylindrical Symmetry. Particle Accelerators 7: 213-222.

8. Kunz, J.C., Kehler, T.F., and Williams, M.D. (1984) Applications Development lising a Hybrid AI Development System. AI Magazine 5, 3: $11-54$.

9. Novak, G. (1983) GLISP. AI Magazine 4, 3: 37-47.

1C. Presoman, R.S. (1982) Software Engineering - A Practitioner's Approach. McGraw-Hill, NY.

11. Sowa, J.F. (1084) Conceptual Structures -- Information Processing in Mind and Machine. Addisoo-Wesley, Reading, MA: 343.

12. Stefk, M., Bobrow, D.G., Mittal, S., and Conway, L. (1083) Kanwledge Programming in LOOPS. AI Magazine 4, 3: 3-13. 